\title{
RELATIVE IMPORTANCE OF LATERAL AND VERTICAL SHEAR ON RUTFORD ICE STREAM, ANTARCTICA
}

\author{
by
}

\author{
R.M. Frolich and C.S.M. Doake
}

(British Antarctic Survey, Natural Environment Research Council, High Cross, Madingley Road, Cambridge CB3 OET, England)

\section{ABSTRACT}

Survey data from three transverse profiles across Rutford Ice Stream show that most of the shear deformation occurs in boundary layers about $10 \mathrm{~km}$ wide on both sides of the glacier. There is a central part, also about $10 \mathrm{~km}$ wide, where lateral shear-stress gradients are not significantly different from zero. This implies that friction from the side walls does not impede the flow in the middle of the glacier. Instead, a basal shear stress of around $40 \mathrm{kPa}$ is required in order to provide the necessary restraint. Even then, only a small proportion of the forward movement will be caused by internal deformation of the ice and the remainder must arise from sliding or rapid deformation at or near the base of the glacier. Although the present analysis does not consider in detail the variation with depth in stresses and strain-rates, the formulation of the problem suggests that a self-consistent solution can be found for the distribution of basal and vertical shear stresses.

\section{INTRODUCTION}

A survey network of more than 200 aluminium poles on Rutford Ice Stream (Fig. 1) has been described and preliminary results have been presented (Stephenson and Doake 1982, Doake and others 1987, Frolich and others 1987). A longitudinal stress-gradient equation has been used to partition the resistive forces between marginal (side-wall)

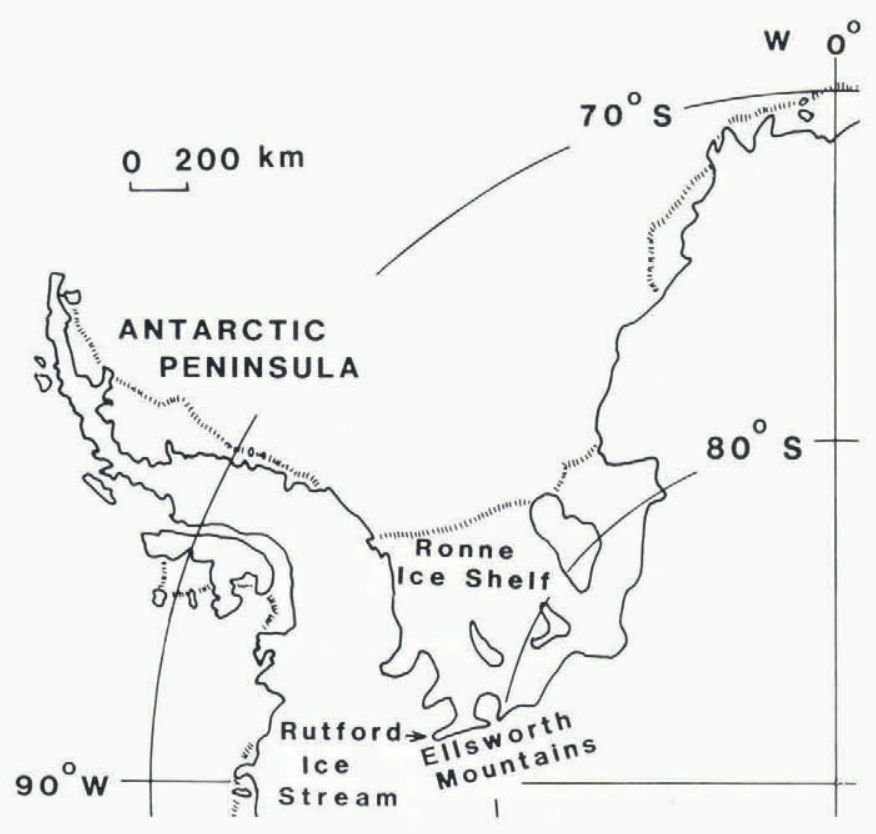

Fig. 1. Location of Rutford Ice Stream.

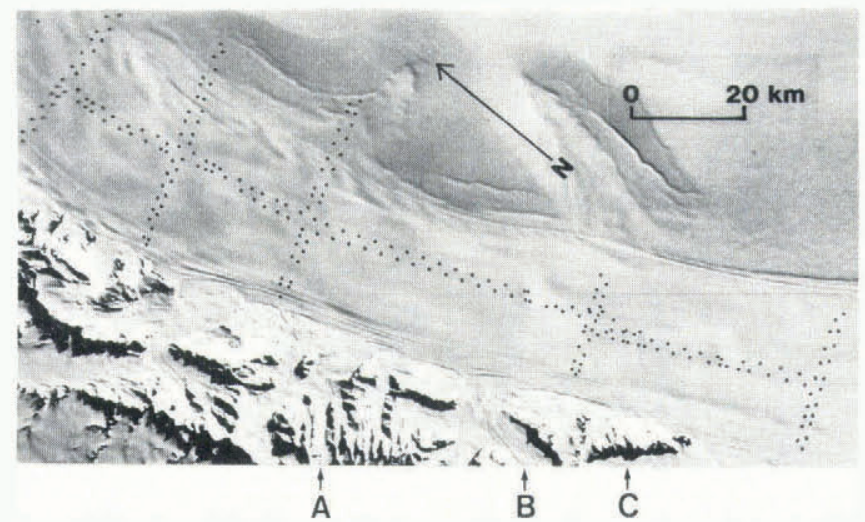

Fig. 2. Full stake network superimposed on a Landsat image of Rutford Ice Stream (courtesy of Dr B. Lucchitta, U.S.G.S., Flagstaff, AZ 86001 , U.S.A.). The position of the longitudinal network discussed in this paper lies between $\mathrm{A}$ and $\mathrm{C}$, crossing a prominent surface knoll at B. The direction of ice flow is from left to right, the Ellsworth Mountains are at the bottom of the image and Fletcher Promontory is at the top.

shear, basal friction and localized bending (Frolich and others 1987), in an attempt to understand the processes opposing the gravitational driving force. A $60 \mathrm{~km}$ longitudinal line of the network (Fig. 2) has been treated for its force balance in this way. The horizontal shear stresses generated by contact with rock and slower-moving ice at the glacier margins were represented by yield stresses of $100 \mathrm{kPa}$ acting at these margins, with a constant transverse gradient of shear stress between them. The subsequent analysis of transverse profiles on the network, at each end of the $60 \mathrm{~km}$ longitudinal line, together with results from the down-stream transverse line (Fig. 2), has allowed this approximation to be discarded and a more confident assessment to be made of where the major restraint occurs.

\section{DATA ACQUISITION AND ANALYSIS}

The data were obtained from conventional survey techniques and radar sounding. Survey control was provided by Magnavox MX1502B doppler satellite receivers, using the Transit system. Collection of the data is described in more detail in Doake and others (1987) and Frolich and others (1987). Stations were arranged in double lines, with typical separations of $2-3 \mathrm{~km}$. Positions and velocities for the stations were obtained from the solution of time-dependent observation equations (Wager and others 1980), and the residuals were used to estimate uncertainties in the solutions and in the strain-rates derived from them. Random errors in observation typically contribute an error of about $10^{-4} \mathrm{a}^{-1}$ in magnitude and $1^{\circ}$ in orientation of the principal axes of 
strain-rate. Surface velocity, surface elevation and ice thickness are treated as varying linearly over each triangle of adjacent stations, with average values and gradients applying at the centroids. Stations were generally surveyed twice, with an interval of about 1 year. Any redundancy is used for checking and estimating uncertainties, so values for gradients in strain-rates in both directions normally exist only at the intersections of the longitudinal line with transverse lines.

The longitudinal stress-gradient equation used is similar to that given by Frolich and others (1987), with the exception that the three components of the force acting at the base have been separated, giving

$$
\begin{gathered}
\left|\int_{z_{\mathrm{b}}}^{z_{\mathrm{s}}}\left[2 \sigma_{x}^{\prime}+\sigma_{y}^{\prime}\right] \mathrm{d} z\right|=\left|\int_{x^{\prime}}^{z_{\mathrm{s}}}\left[2 \sigma_{x}^{\prime}+\sigma_{y}^{\prime}\right] \mathrm{d} z\right|_{\mathrm{b}}- \\
-\int_{x^{\prime}}^{\mathrm{L}}\left[\rho g \frac{\partial z_{\mathrm{s}}}{\partial x} H\right] \mathrm{d} x+\int_{x^{\prime}}^{\mathrm{L}}\left[\frac{\partial}{\partial y}\left[\int_{z_{\mathrm{b}}}^{z_{\mathrm{s}}} \sigma_{x y} \mathrm{~d} z\right] \mathrm{d} x+\right. \\
+\int_{x^{\prime}}^{\mathrm{L}}\left[-\sigma_{x z}\left(z_{\mathrm{b}}\right]+\sigma_{x}^{\prime}\left[z_{\mathrm{b}}\right) \frac{\partial z_{\mathrm{b}}}{\partial x}+\sigma_{x y}\left[z_{\mathrm{b}}\right] \frac{\partial z_{\mathrm{b}}}{\partial y}\right] \mathrm{d} x+ \\
+\left[\int_{z_{\mathrm{b}}}^{z_{\mathrm{s}}} \int_{z^{\prime}}^{z_{\mathrm{s}}}\left[\frac{\partial \sigma_{x z}}{\partial x}+\frac{\partial \sigma_{y z}}{\partial y}\right] \mathrm{d} z \mathrm{~d} z^{\prime}\right]_{x^{\prime}}^{\mathrm{L}}
\end{gathered}
$$

where the stresses normal and tangential to the upper surface have been taken to be zero ( $x$ - and $y$-axes are horizontal, with $x$ positive down-stream; the $z$-axis is vertical, positive upwards with surface at $z_{\mathrm{S}}$ and base at $z_{\mathrm{b}}$; $H$ is the ice thickness, $\rho$ is the mean ice density, and $g$ is the gravitational acceleration). This equation can be shown to be equivalent both to the form obtained by Collins (1968) in the case of vanishing transverse gradients and to similar formulations due to Robin (1967), Nye (1969), Budd (1970), Hutter (1983), MacAyeal and others (1986), Morland (1987) and Whillans and van der Veen (1988, this volume). The last term in Equation (1) is often known as the " $T$ " term (Nye 1969). A similar equation exists for the other horizontal direction, but we do not have values for second spatial derivatives of velocity over a wide area which would enable an arbitrary path of integration to be taken. The $x$-coordinate has therefore been taken to agree closely with the line of the network and the mean flow direction. Equation (1) thus represents a force balance per unit width integrated along an approximate flow line between a point $x^{\prime}$ and a down-stream limit $L$. For the calculation of stresses from field data, an effective viscosity $u$ was defined, using a flow law of the form

$$
\begin{aligned}
\sigma_{i j}^{\prime} & =\dot{\varepsilon}_{i j} \dot{E}^{(1-n) / n_{B}} \\
2 \mathrm{~V} & =B \dot{E}^{(1-n) / n}
\end{aligned}
$$

where $\sigma_{i j}^{\prime}$ is the stress deviator, $\dot{\varepsilon}_{i j}$ is the strain-rate, $2 \dot{E}^{2}$ is the second invariant of the strain-rate tensor, and $B$ is a temperature-dependent parameter whose mean value was taken to be $4 \times 10^{5} \mathrm{~Pa} \mathrm{a}^{1 / 3}$ for $n=3$. Although the index $n$ is usually assumed to be 3 , implying non-linear flow, there is some doubt about experimental evidence from the field for this value, and a linear viscosity where $n=1$ may be equally applicable (Doake and Wolff 1985, Paterson 1985, Wolff and Doake 1986). Only the strain-rates measured at the surface were available for the calculation of values for $\dot{E}$, and incompressible flow was assumed. If vertical shear is significant, then the calculated effective viscosities will be too high and the stresses will be overestimated. As no information on variations in parameters with depth is available, integrals over depth have been approximated by assuming that the strain-rates are independent of depth, as would be expected in an ice shelf. The validity of this assumption is discussed later.

The force balance may be written in symbolic form

$$
V\left(x^{\prime}\right)=V(L)-D F-R F
$$

where $V$ is the viscous response, $D F$ is the difference in driving force between $x^{\prime}$ and $L$, and $R F$ is the difference in restraining force between $x^{\prime}$ and $L$ (the sum of the last three integrals in Equation (1)). The variation in these terms along the longitudinal line is shown in Figure 3.

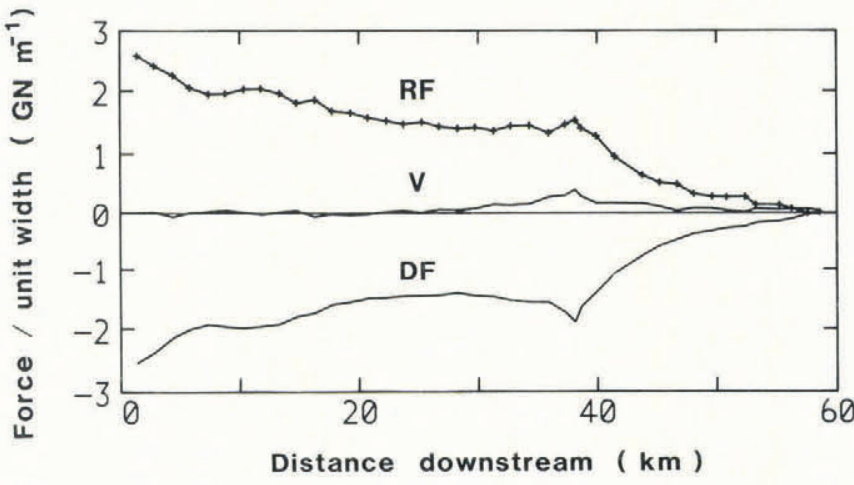

Fig. 3. Terms in the force-balance equation for the longitudinal line between $\mathrm{A}$ and $\mathrm{C}$ in Figure 2. The symbolic names are explained in the text $(R F$ is the restraint, $V$ is the viscous response, $D F$ is the driving force).

\section{DISCUSSION}

Elevation and velocity profiles for the three transverse lines are shown in Figures 4 and 5 . The two lower lines ((b) and (c)) cover the central part of the ice stream and

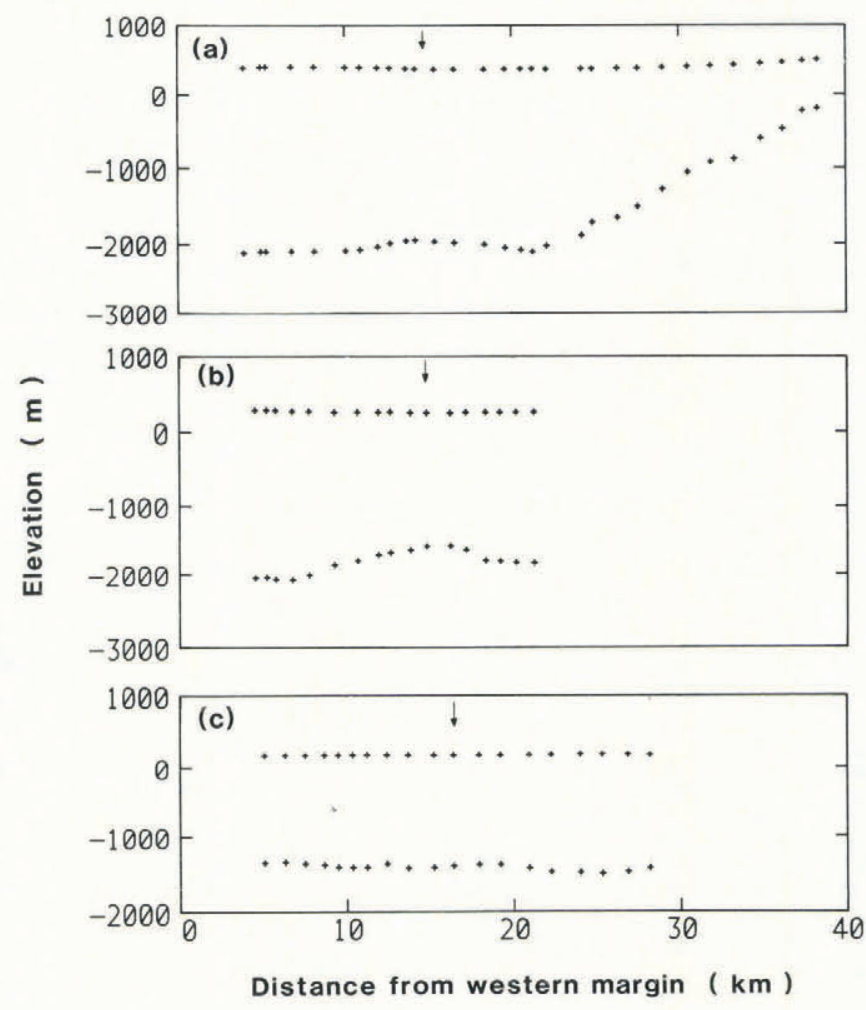

Fig. 4. Surface-elevation and bed profiles for the three lower (down-stream) transverse lines shown in Figure 2 ((a) is the middle line, (c) is the line farthest down-stream). Arrows indicate the approximate location of the longitudinal line. 

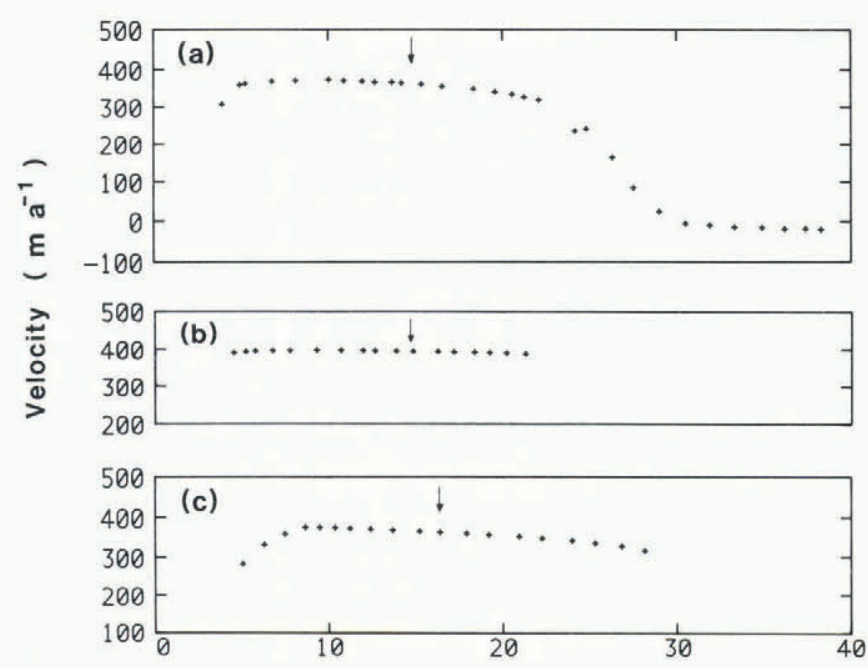

Distance from western margin $(\mathrm{km})$

Fig. 5. Velocity profiles for the three lower (down-stream) transverse lines shown in Figure 2 ((a) is the middle line, (c) is the line farthest down-stream). The direction of the horizontal velocity is along a bearing of $160^{\circ}$ true. Arrows indicate the approximate location of the longitudinal line.

do not penetrate the marginal zones to any significant extent. The up-stream line (a), however, crosses the boundary on to Fletcher Promontory, where there appears to be a small component of flow in the direction opposite to that of the ice stream, due to ice discharging from the prominent cirque. In the main body of the ice stream the greatest variation in ice thickness occurs in the middle transverse profile (b), where there is a relief of around $500 \mathrm{~m}$ in the subglacial topography. The longitudinal stake line crosses this transverse profile near the crest, which appears to be a continuation of the bedrock step, manifested on the surface by a knoll found farther up-stream (Frolich and others 1987).

The thickest ice and deepest glacial bed lie on the western side of the ice stream, close to the Ellsworth Mountains. The maximum forward velocity is also displaced towards this side. Horizontal shear strain-rates $\left(\dot{\varepsilon}_{x y}\right)$ for the upper two transverse lines pass through zero at the same position as the maximum value of the velocity,

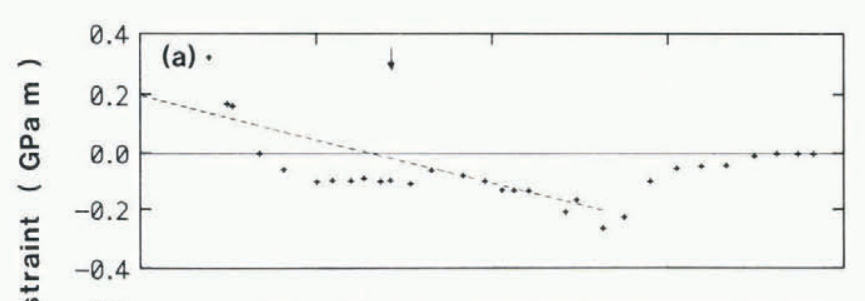

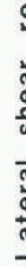
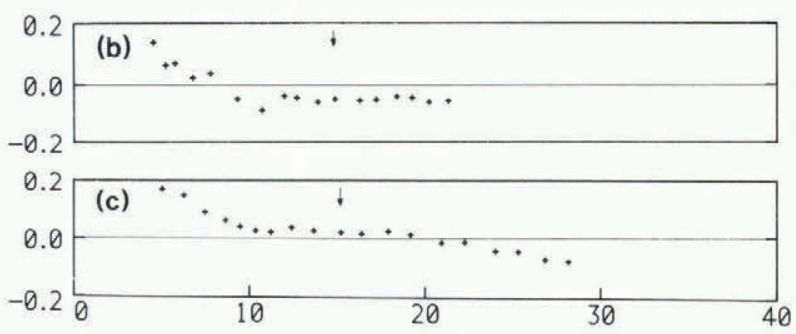

Distance from western margin $(\mathrm{km})$

Fig. 6. Profiles of lateral shear stress integrated over depth for the three lower (down-stream) transverse lines shown in Figure 2 ((a) is the middle line, (c) is the line farthest down-stream). The dotted line shows a constant shear-stress gradient which assumes a shear stress of $100 \mathrm{kPa}$ at each margin. Arrows indicate the approximate location of the longitudinal line. as expected. The surface strain-rates have been converted to depth-integrated shear stresses, shown in Figure 6, by the formula

$$
\int_{z_{\mathrm{b}}}^{z_{\mathrm{s}}} \sigma_{x y} \mathrm{~d} z=2 v H \dot{\varepsilon}_{x y}
$$

The parameters $n$ and $B$ in the flow law are assumed to be constant across a profile, and the depth-averaged value of $\dot{\varepsilon}_{x y}\left(\bar{\varepsilon}_{x y}\right)$ is assumed to bear a constant relationship to the surface value, i.e.

$$
\overline{\dot{\varepsilon}_{x y}}=\beta \dot{\varepsilon}_{x y}
$$

where $B$ is independent of $y$. The restraint from side-wall (marginal) shear (SW) arises from the gradient of the shear stress in the $y$-direction:

$$
\mathrm{SW}=\frac{\partial}{\partial y}\left[\int_{z_{\mathrm{b}}}^{z_{\mathrm{S}}} \sigma_{x y} \mathrm{~d} z\right]
$$

so a value of $B$ constant with $y$ will be equivalent to a scale change in the magnitude of the shear-restraint profiles shown in Figure 6 . These profiles do not have a constant slope, as would be expected if side-wall shear extended its influence uniformly across the glacier and as is frequent]y assumed to be the case for ice shelves (Thomas 1973). Instead, a boundary layer about $10 \mathrm{~km}$ wide on the western margin experiences a high gradient and is followed by a central region where the gradients are very small and not significantly different from zero. The gradients increase again in the eastern margin.

The highest calculated horizontal shear stress, at the western margin of the upper line, is about $160 \mathrm{kPa}$. Such a high value suggests that the effective viscosity may have been overestimated, due in part to assuming that it is constant with depth, whereas warmer deeper ice should be softer than ice at the surface. The ice at the western margin will generally have come from steep valley glaciers in the Ellsworth Mountains and have a complicated stress history. Its incorporation into the boundary may therefore result in anisotropies in the fabric and a more easily deformed layer. This could also apply at the eastern margin, because ice floating slowly off Fletcher Promontory forms a boundary layer. MacAyeal and others (1986) suggested that the boundary between fast-flowing ice shelf and land-fast ice may be weakened by faulting and they described the boundary in terms of a coulomb rheology. This may be equally applicable in the case of ice streams. Alternatively, strain heating in regions of high shear or inadequacies in the flow law may both be important.

It seems likely, however, that the ice rheology changes little across the middle third of the ice stream, and that the flatness of the lateral shear profiles reflects a lack of restraint from the margins. This leaves only forces at the base and the " $T$ " term to balance the variations in driving force. The " $T$ " term is frequently assumed to average to zero over distances of more than a few ice thicknesses (Kamb and Echelmeyer 1986). If this is indeed the case, then forces acting at the base must account for almost the entire variation in restraining force $(R F)$ along the network (Fig. 3).

This is a surprising result in view of the high surface velocities and the possibility that the basal ice is at its pressure-melting point. The longitudinal average value of the driving stress is about $40 \mathrm{kPa}$, which must be balanced by a basal shear stress of about the same magnitude. Taking the calculated values of effective viscosity and assuming that the variation in the vertical shear stress $\left(\sigma_{x z}\right)$ is linear with depth, then a basal shear stress of $40 \mathrm{kPa}$ would give a difference between surface and basal velocities of the order of $10 \mathrm{~m} \mathrm{a}^{-1}$ (the measured surface velocity varies from about $360 \mathrm{~m} \mathrm{a}^{-1}$ to $400 \mathrm{~m} \mathrm{a}^{-1}$ along the longitudinal line). This difference is probably too small to be detectable from the surface, either with radar-fading patterns (Doake 1975) or from mass-flux calculations, suggesting that direct observations at depth may be required. 
The third transverse profile (Fig. 6(c)) lies down-stream of sites where tidal flexure has been observed (Stephenson 1984) and may be entirely on floating ice. A difference in gradient between the western margin and central regions of the ice stream is still apparent, though less distinctly than on the other two profiles. The contribution of lateral shear to the restraining force must therefore still be small, but in this case the much smaller surface slopes mean that the driving force which must be balanced is also small. The ice stream is in longitudinal compression here (Stephenson and Doake 1982), further reducing the restraint necessary for balance.

Although the variation in stresses with depth has not been treated rigorously here, the conclusion that marginal shear is unimportant near the centre of the ice stream suggests that a two-dimensional simplification may be made that would allow a self-consistent solution for the distribution of basal and vertical shear stress $\left(\sigma_{x z}\right)$. Figure 3 shows that the viscous terms (the one on the left-hand side of Equation (1) and the first term on the right-hand side) containing the direct stresses are much smaller than either the driving force $D F$ or the restraining forces $R F$. Therefore, not knowing the variation in $\dot{\varepsilon}_{x}$ or $\dot{\varepsilon}_{y}$ with depth should not lead to large errors when calculating $R F$. By ignoring gradients in the $y$-direction in the $R F$, terms in Equation (1), and neglecting $\sigma_{x}^{\prime} \frac{\mathrm{d} z_{\mathrm{b}}}{\partial x}$, only the vertical shear stress $\sigma_{x z}$ appears in the resistive forces. In the middle of an ice stream a simple linear variation in $\sigma_{x z}$ with depth may be appropriate. Thus, taking $\sigma_{x z}=0$ on the surface should allow $\sigma_{x z}\left(z_{\mathrm{b}}\right)$ to be calculated as a function of $x$.

In conclusion, it appears that in this part of Rutford Ice Stream there are two distinct flow regimes: a marginal zone in which side-wall shear is important, and a central region where basal friction dominates. The transition from ice-sheet to ice-shelf-type flow probab]y occurs in a non-uniform manner, in which several different processes interpenetrate along the ice stream and are responsible for the overall force balance.

\section{REFERENCES}

Budd, W.F. 1970. The longitudinal stress and strain-rate gradients in ice masses. J. Glaciol., 9(55), 19-27.

Collins, I.F. 1968. On the use of the equilibrium equations and flow law in relating the surface and bed topography of glaciers and ice sheets. J. Glaciol., 7(50), 199-204.
Doake, C.S.M. 1975. Bottom sliding of a glacier measured from the surface. Nature, 257(5529), 780-782.

Doake, C.S.M., and E.W. Wolff. 1985. Flow law for ice in polar ice sheets. Nature, 314(6008), 255-257.

Doake, C.S.M., R.M. Frolich, D.R. Mantripp, A.M. Smith, and D.G. Vaughan. 1987. Glaciological studies on Rutford Ice Stream, Antarctica. J. Geophys. Res., 92(B9), 8951-8960.

Frolich, R.M., D.R. Mantripp, D.G. Vaughan, and C.S.M. Doake. 1987. Force balance of Rutford Ice Stream, Antarctica. IAHS Publ. 170 (Symposium at Vancouver 1987 - The Physical Basis of Ice Sheet Modelling), 323-331.

Hutter, K. 1983. Theoretical glaciology: material science of ice and the mechanics of glaciers and ice sheets. Dordrecht, etc., D. Reidel Publishing Company.

Kamb, B., and K.A. Echelmeyer. 1986. Stress-gradient coupling in glacier flow: IV. Effects of the "T" term. $J$. Glaciol., 32(112), 342-349.

MacAyeal, D.R., S. Shabtaie, C.R. Bentley, and S.D. King. 1986. Formulation of ice shelf dynamic boundary conditions in terms of a Coulomb rheology. J. Geophys. Res., 91(B8), 8177-8191.

Morland, L.W. 1987. Unconfined ice-shelf flow. In Veen, C.J. van der, and J. Oerlemans, eds. Dynamics of the West Antarctic Ice Sheet. Proceedings of a Workshop held in Utrecht, May 6-8, 1985. Dordrecht, etc., D. Reidel Publishing Company, 99-116.

Nye, J.F. 1969. The effect of longitudinal stress on the shear stress at the base of an ice sheet. J. Glaciol., 8(53), 207-213.

Paterson, W.S.B. 1985. Flow law for ice in polar ice sheets. Nature, 318(6041), 82-83.

Robin, G. de Q. 1967. Surface topography of ice sheets. Nature, 215(5105), 1029-1032.

Stephenson, S.N. 1984. Glacier flexure and the position of grounding lines: measurements by tiltmeter on Rutford Ice Stream, Antarctica. Ann. Glaciol., 5, 165-169.

Stephenson, S.N., and C.S.M. Doake. 1982. Dynamic behaviour of Rutford Ice Stream. Ann. Glaciol., 3, 295-299.

Thomas, R.H. 1973. The creep of ice shelves: theory. J. Glaciol., 12(64), 45-53.

Wager, A.C., C.S.M. Doake, J.G. Paren, and J.L.W. Walton. 1980. Survey reduction for glacier movement studies. Surv. Rev., 25(196), 251-263.

Whillans, I.M., and C.J. van der Veen. 1988. Force budget. Ann. Glaciol., 11, 212.

Wolff, E.W., and C.S.M. Doake. 1986. Implications of the form of the flow law for vertical velocity and age-depth profiles in polar ice. J. Glaciol., 32(112), 366-370. 